\title{
Crystal Growth and Scintillation Properties of Strontium Iodide Scintillators
}

Edgar V. van Loef, Cody M. Wilson, Nerine J. Cherepy, Giulia Hull, Stephen A. Payne, Woon-Seng Choong, William W. Moses, Member, IEEE, and Kanai S. Shah

This work supported by the National Nuclear Security Administration, Office of Defense

Nuclear Nonproliferation, Office of Nonproliferation Research and Development (NA-22) of the U.S. Department of Energy under Contract No. DE-AC02-05CH11231. 


\title{
Crystal Growth and Scintillation Properties of Strontium Iodide Scintillators
}

\author{
Edgar V. van Loef, Cody M. Wilson, Nerine J. Cherepy, Giulia Hull, Stephen A. Payne, Woon-Seng \\ Choong, William W. Moses, Member, IEEE, and Kanai S. Shah
}

\begin{abstract}
Single crystals of $\mathrm{SrI}_{2}: \mathrm{Eu}$ and $\mathrm{SrI}_{2}: \mathrm{Ce} / \mathrm{Na}$ were grown from anhydrous iodides by the vertical Bridgman technique in evacuated silica ampoules. Growth rates were of the order of $5-30 \mathrm{~mm} /$ day. Radioluminescence spectra of $\mathrm{SrI}_{2}: \mathbf{E u}$ and $\mathrm{SrI}_{2}: \mathrm{Ce} / \mathrm{Na}$ exhibit a broad band due to $\mathrm{Eu}^{2+}$ and $\mathrm{Ce}^{3+}$ emission, respectively. The maximum in the luminescence spectrum of $\mathrm{SrI}_{2}: \mathrm{Eu}$ is found at $435 \mathrm{~nm}$. The spectrum of $\mathrm{SrI}_{2}: \mathrm{Ce} / \mathrm{Na}$ exhibits a doublet peaking at 404 and $435 \mathrm{~nm}$ attributed to $\mathrm{Ce}^{3+}$ emission, while additional impurity - or defected - related emission is present at approximately $525 \mathrm{~nm}$. The strontium iodide scintillators show very high light yields of up to 120,000 photons/ $\mathrm{MeV}$, have energy resolutions down to $3 \%$ at $662 \mathrm{keV}$ (Full Width Half Maximum) and exhibit excellent light yield proportionality with a standard deviation of less than $5 \%$ between 6 and $460 \mathrm{keV}$.
\end{abstract}

Index Terms-Alkaline-earth halides, Crystal growth, Energy resolution, Scintillation detectors.

\section{I.INTRODUCTION}

$\mathrm{S}^{\mathrm{e}}$ ecurity applications and nuclear non-proliferation depend on the rapid identification of highly enriched uranium, weapons grade plutonium, radioactive sources and other special nuclear materials. Efficient detection of their gammaray signature is the most common method for identification and requires a scintillator that has a high light yield, good energy resolution, fast scintillation and high effective atomic number. Currently, $\mathrm{LaBr}_{3}: \mathrm{Ce}$ and $\mathrm{CeBr}_{3}$ [1]-[3] provide the best combination of these properties. However, both are moisture sensitive and are prone to cracking during crystal growth [4]. Recently, the alkaline-earth iodides doped with divalent europium, i.e. $\mathrm{SrI}_{2}: \mathrm{Eu}$ and $\mathrm{BaI}_{2}: \mathrm{Eu}$, have been rediscovered as inorganic scintillators that may rival $\mathrm{LaBr}_{3}: \mathrm{Ce}$ and $\mathrm{CeBr}_{3}$. Initially discovered by Hofstadter in 1968 [5], recent research indicates that these materials exhibit high light yields and show good energy resolution [6].

In this paper we report on the crystal growth and

\footnotetext{
Manuscript received June 18, 2008. This work was supported in part by the Domestic Nuclear Detection Office in the Department of Homeland Security via Lawrence Livermore National Laboratory.

Edgar V. van Loef, Cody M. Wilson, and Kanai S. Shah are with Radiation Monitoring Devices, Inc., Watertown, MA 02472 USA (phone: 617-668-6922; fax: 617-926-9980; e-mail: EvanLoef@RMDInc.com).

Nerine J. Cherepy, Giulia Hull, and Stephen A. Payne are with Lawrence Livermore National Laboratory, Livermore, CA 94550 USA (e-mail: cherepy1@1lnl.gov).

Woon-Seng Choong, and William W. Moses are with Lawrence Berkeley National Laboratory, Berkeley, CA 94720 USA (e-mail: wwmoses@1bl.gov).
}

scintillation properties of strontium iodide scintillators doped with $\mathrm{Eu}^{2+}$ and $\mathrm{Ce}^{3+}$. Radioluminescence, pulse height and scintillation decay time spectra are presented.

\section{II.CRYSTAL GROWTH}

Single crystals of $\mathrm{SrI}_{2}: \mathrm{Eu}$ and $\mathrm{SrI}_{2}: \mathrm{Ce} / \mathrm{Na}$ doped with different $\mathrm{Eu}^{2+}$ and $\mathrm{Ce}^{3+}$ concentrations were grown in silica ampoules using the vertical Bridgman technique. Sodium iodide was used as charge compensation, mandated by the substitution of trivalent cerium for divalent strontium. The melting point of $\mathrm{SrI}_{2}$ is approximately $538^{\circ} \mathrm{C}$. $\mathrm{SrI}_{2}$ has the orthorhombic crystals structure with space group Pbca [7]. Based on structure and lattice parameters, the density of $\mathrm{SrI}_{2}$ is $4.59 \mathrm{~g} / \mathrm{cm}^{3}$.

Anhydrous $\mathrm{SrI}_{2}$ beads (Aldrich, 99.99\%), EuI ${ }_{2}$ powder (Aldrich, 99.9\%), $\mathrm{CeI}_{3}$ beads (Aldrich, 99.99\%), and $\mathrm{NaI}$ beads (Aldrich, 99.999\%) were used as starting materials. The starting materials were loaded into silica ampoules in a nitrogen-purged glovebox. Next, the ampoules were closed from the atmosphere by use of a vacuum valve and subsequently connected to a Varian Vac Sorb pump. The ampoules were evacuated to approximately $10^{-3}$ Torr while heated with a heating tape to approximately $150^{\circ} \mathrm{C}$ to remove any residual moisture. After several hours, the heating tape was removed and the ampoules were sealed. The strontium iodides were kept cool during the entire sealing operation by wrapping a wet towel around the ampoule. This prevented thermal decomposition of the iodides due to heat from the torch.

We used vertical Bridgman furnaces to grow the strontium iodides. Crystals were grown by melting the entire charge prior to the start of the run and subsequently lowering the ampoule through the hot zone. Sealed ampoules were lowered through the hot zone of the furnace at a predetermined rate of 5 to 30 $\mathrm{mm} /$ day. Subsequently, solidification starts at the capillary tip, which acts as a seed for the random crystal growth along the length of the capillary and the remainder of the crystal. The temperature maximum of the zone was set at $50^{\circ} \mathrm{C}$ above the melting point of the strontium iodide. The temperature gradient is typically $25^{\circ} \mathrm{C} / \mathrm{cm}$, but can vary from the outer core to the end of the furnace from 3 to $75^{\circ} \mathrm{C} / \mathrm{cm}$.

The highest quality strontium iodide crystals were obtained with $\mathrm{SrI}_{2}$ :Eu grown at rates of $5-10 \mathrm{~mm} /$ day. As an example, 


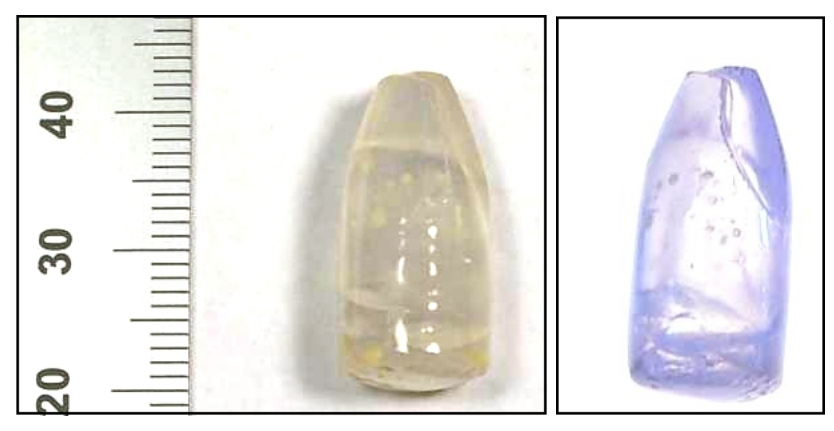

Fig. 1. Photograph of a $\operatorname{SrI}_{2}: 8 \%$ Eu ingot. The photograph on the left was taken with ambient light, while the photograph on the right was taken with the ingot placed on a light box.

Fig. 1 shows a photograph of a $\operatorname{SrI}_{2}: 8 \%$ Eu ingot. The ingot is about $10 \mathrm{~mm}$ in diameter and $24 \mathrm{~mm}$ long. The yellowish color of the ingot under ambient light is due to a thin layer of mineral oil on the surface of the ingot. The bluish haze of the ingot exposed to transmitting light is attributed to absorption and emission of $\mathrm{Eu}^{2+}$. Almost all $\mathrm{SrI}_{2}: \mathrm{Eu}$ ingots are optically clear, show minimal cracking and appear to have minimal $\mathrm{Eu}^{2+}$ segregation, whereas $\mathrm{SrI}_{2}: \mathrm{Ce} / \mathrm{Na}$ ingots have a pale yellow tint and show some $\mathrm{Ce}^{3+}$ segregation.

\section{III.Scintillation Properties}

\section{A.Radioluminescence}

Radioluminescence spectra were recorded with a Philips Xray tube having a $\mathrm{Cu}$ anode operated at $30 \mathrm{kV}$ and $20 \mathrm{~mA}$. The scintillation light was dispersed through a McPherson 234/302 monochromator equipped with a holographic grating (1200 grooves $/ \mathrm{mm}$ ) and subsequently detected with a Hamamatsu R2059 photomultiplier tube (PMT). Radioluminescence spectra of $\mathrm{SrI}_{2}: 0.5 \% \mathrm{Eu}$ and $\mathrm{SrI}_{2}: 0.5 \% \mathrm{Ce} / \mathrm{Na}$ are shown in Fig. 2. For $\operatorname{SrI}_{2}: 0.5 \% \mathrm{Eu}$ the spectrum consists of a single broad band due to $\mathrm{Eu}^{2+} 5 \mathrm{~d} \rightarrow 4 \mathrm{f}$ emission, peaking at $435 \mathrm{~nm}$ [6]. In contrast, the spectrum of $\operatorname{SrI}_{2}: 0.5 \% \mathrm{Ce} / \mathrm{Na}$ exhibits a doublet peaking at 404 and $435 \mathrm{~nm}$ attributed to $\mathrm{Ce}^{3+}$ luminescence, while additional impurity - or defected - related emission is

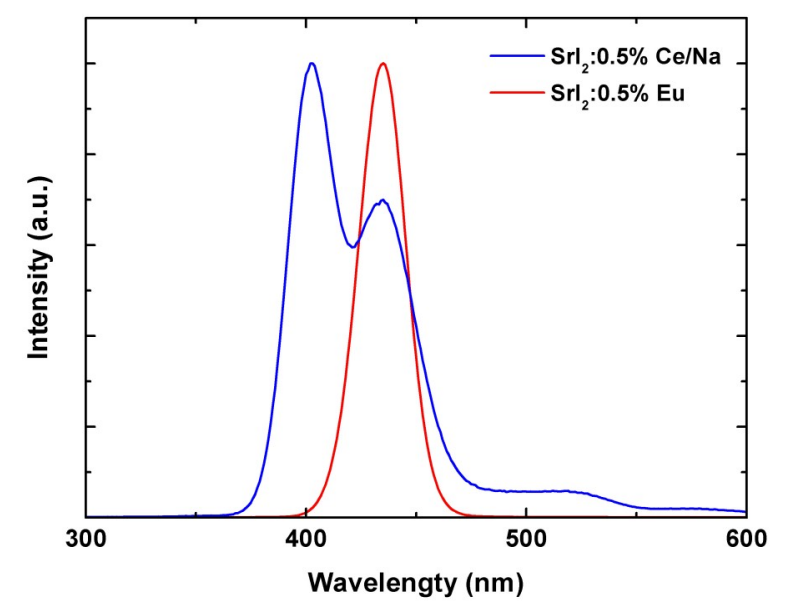

Fig. 2. Radioluminescence spectrum of $\operatorname{SrI}_{2}: 0.5 \%$ Eu and $\mathrm{SrI}_{2}: 0.5 \% \mathrm{Ce} / \mathrm{Na}$. present at approximately $525 \mathrm{~nm}$.

\section{B.Scintillation Decay}

Scintillation decay time spectra were recorded using a ${ }^{137} \mathrm{Cs}$ gamma ray source and a Tektronix TDS 220 oscilloscope connected to the output of a PMT. Fig. 3 shows the scintillation decay time spectra of $\operatorname{SrI}_{2}: 0.5 \% \mathrm{Eu}$ and $\mathrm{SrI}_{2}: 0.5 \%$ $\mathrm{Ce} / \mathrm{Na}$ under ${ }^{137} \mathrm{Cs}$ gamma ray excitation. A simple exponential decay time model was used to fit the data. In the case of $\mathrm{SrI}_{2}: 0.5 \% \mathrm{Eu}$, the scintillation decay curve can be described by a single exponential decay time model with a time constant of $1.1 \mu \mathrm{s}$. For higher Eu concentrations, the time constant does not change significantly. The scintillation decay curve of $\mathrm{SrI}_{2}: 0.5 \% \mathrm{Ce} / \mathrm{Na}$ can be described by a two-component exponential decay time model; a principle decay component that contributes about $25 \%$ to the total light yield with a $27 \mathrm{~ns}$ time constant, and a second decay component with a $450 \mathrm{~ns}$ time constant. The principal decay component of $\operatorname{SrI}_{2}: 2 \%$ $\mathrm{Ce} / \mathrm{Na}$ contributes about $46 \%$ to the total light yield and has a $33 \mathrm{~ns}$ time constant. The remaining light is emitted by a $570 \mathrm{~ns}$ decay component.

\section{C.Light yield and Energy resolution}

Pulse-height spectra were recorded with a Hamamatsu R2059 PMT. The output of the PMT was connected to a Canberra 2005 preamplifier and a Canberra 2020 spectroscopic amplifier. Crystals were optically coupled onto the window of the PMT using Bicron BC-630 optical grease. To minimize losses in light yield, crystals were wrapped in several layers of 0.1-mm UV reflecting Teflon tape. Nitrogen was flushed around the crystal to prevent hydration of the surface during measurement. Light yields expressed in photoelectrons per megaelectronvolt $(\mathrm{MeV})$ of absorbed gamma ray energy (phe/MeV) were determined by comparing the peak position of the $662 \mathrm{keV}$ full energy peak in the pulse height spectra with the position of the peak in the spectrum of single photoelectrons. The absolute light yield, expressed in



Fig. 3. Scintillation decay time spectra of $\mathrm{SrI}_{2}: 0.5 \% \mathrm{Eu}$ and $\mathrm{SrI}_{2}: 0.5 \% \mathrm{Ce} / \mathrm{Na}$ under ${ }^{137} \mathrm{Cs}$ gamma ray excitation. 


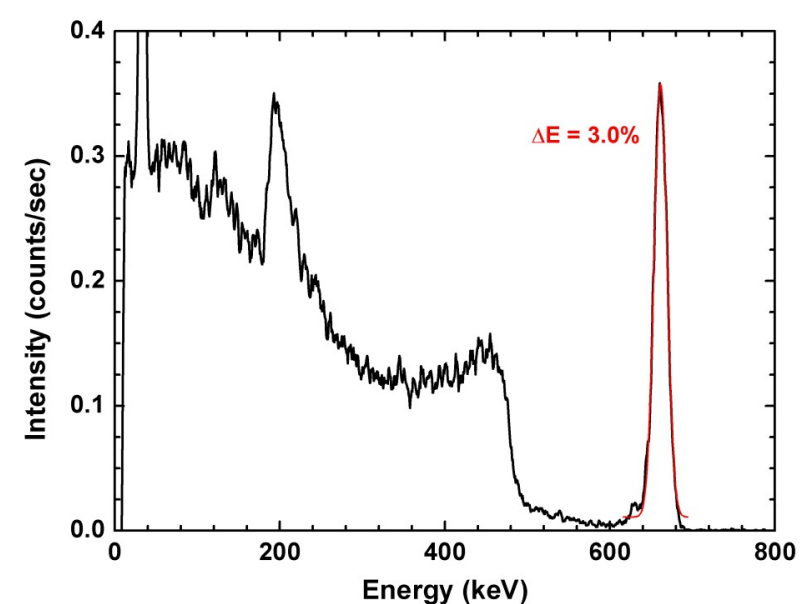

Fig. 4. Pulse height spectrum of $\mathrm{SrI}_{2}: 5 \%$ Eu under ${ }^{137} \mathrm{Cs}$ gamma ray excitation using a shaping time of $4 \mu \mathrm{s}$.

photons per $\mathrm{MeV}$ of absorbed gamma ray energy $(\mathrm{ph} / \mathrm{MeV})$ was determined from the detection efficiency of the PMT. The detection efficiency was assumed to be $21 \%$ and $23 \%$ for $\mathrm{SrI}_{2}: \mathrm{Eu}$ and $\mathrm{SrI}_{2}: \mathrm{Ce} / \mathrm{Na}$, respectively.

Fig. 4 shows the pulse height spectrum of $\operatorname{SrI}_{2}: 5 \%$ Eu under ${ }^{137} \mathrm{Cs}$ gamma ray excitation using a shaping time of $4 \mu \mathrm{s}$. Based on the position of the full energy peak and the position of that for single electrons, we estimated light yield of this crystal to be about $120,000 \mathrm{ph} / \mathrm{MeV}$. This light yield is among the highest values obtained with inorganic scintillators. A light yield of $85,000 \mathrm{ph} / \mathrm{MeV}$ was reported previously for $\mathrm{SrI}_{2}: \mathrm{Eu}$ by Cherepy et al. [6]. The energy resolution of the $662 \mathrm{keV}$ full energy peak measured with $\operatorname{SrI}_{2}: 5 \% \mathrm{Eu}$ is about $3 \%$ (FWHM). This is substantially better than the energy resolution of 6 to $7 \%$ (FWHM) at $662 \mathrm{keV}$ obtained with established scintillators such as NaI:Tl and CsI:Tl, while rivaling that of $\mathrm{LaBr}_{3}: \mathrm{Ce}$ scintillators.

In contrast to $\mathrm{SrI}_{2}: \mathrm{Eu}, \mathrm{SrI}_{2}: \mathrm{Ce} / \mathrm{Na}$ crystals show lower light yields and exhibit worse energy resolution. For $\mathrm{SrI}_{2}: 0.5 \%$ $\mathrm{Ce} / \mathrm{Na}$ we measured a light yield of $16,000 \mathrm{ph} / \mathrm{MeV}$ and obtained an energy resolution of $6.4 \%$ at $662 \mathrm{keV}$ (FWHM), whereas for $\mathrm{SrI}_{2}: 2 \% \mathrm{Ce} / \mathrm{Na}$ we measured a light yield of about $10,000 \mathrm{ph} / \mathrm{MeV}$ and an energy resolution of about $12 \%$ at 662 $\mathrm{keV}$ (FWHM) . Whether this is due to the large concentration gradient of $\mathrm{Ce}^{3+}$ and $\mathrm{Na}^{+}$in $\mathrm{SrI}_{2}$, due to the lesser optical quality of the crystals, or a combination of both is unknown.

\section{D.Proportionality}

Light yield proportionality as function of electron energy was measured using the scintillation light yield nonproportionality characterization instrument (SLYNCI) at Lawrence Livermore National Laboratory [8]. $\mathrm{SrI}_{2}$ :Eu exhibits excellent light yield proportionality as function of electron energy [6], rivaling that of $\mathrm{LaBr}_{3}$ :Ce. Light yield proportionality as function of gamma ray energy was obtained by measuring the light yield of $\mathrm{SrI}_{2}: \mathrm{Eu}$ under gamma ray excitation using different isotopes such as ${ }^{22} \mathrm{Na}(511 \mathrm{keV}$ and

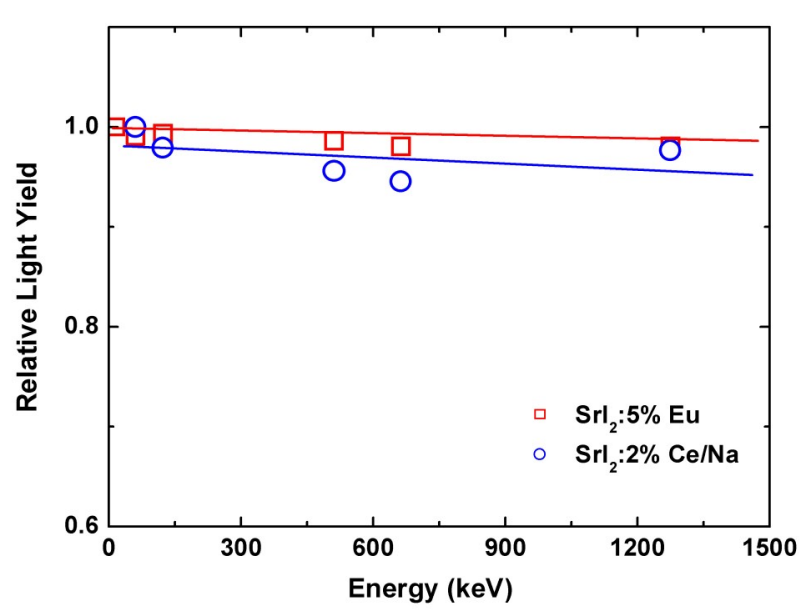

Fig. 5. Light yield proportionality as function of gamma ray energy of $\mathrm{SrI}_{2}: 5 \%$ Eu and $\mathrm{SrI}_{2}: 2 \% \mathrm{Ce} / \mathrm{Na}$.

$1.274 \mathrm{MeV}),{ }^{57} \mathrm{Co}$ (14 keV X-rays, $122 \mathrm{keV}$ gamma rays), ${ }^{137} \mathrm{Cs}(662 \mathrm{keV})$, and ${ }^{241} \mathrm{Am}(60 \mathrm{keV})$. From the measured position of the full energy peak and the known gamma ray energy for each isotope, the light yield at each gamma ray energy was estimated. Subsequently, the data points were normalized with respect to the light yield at $662 \mathrm{keV}$. The results for $\mathrm{SrI}_{2}: 5 \% \mathrm{Eu}$ and $\mathrm{SrI}_{2}: 2 \% \mathrm{Ce} / \mathrm{Na}$ are shown in Fig. 5. $\mathrm{SrI}_{2}: 5 \% \mathrm{Eu}$ demonstrates a remarkable linear response, similar to the response as function of electron energy. The deviation from linearity is less than $2 \%$ over the energy range from 14 to $1274 \mathrm{keV}$. $\mathrm{SrI}_{2}: 2 \% \mathrm{Ce} / \mathrm{Na}$ also proves to be very proportional as function of gamma ray energy with a deviation of less than $6 \%$ over the energy range from 60 to $1274 \mathrm{keV}$. Although the energy resolution of $\mathrm{SrI}_{2}: \mathrm{Ce} / \mathrm{Na}$ at present is poor, its good proportionality indicates that when uniform crystals are produced with good optical quality, energy resolution may improve as well.

\section{IV.SUMMARY}

Table I presents a summary of the scintillation properties of $\mathrm{SrI}_{2}: \mathrm{Eu}$ and $\mathrm{SrI}_{2}: \mathrm{Ce} / \mathrm{Na}$. Light yield, energy resolution, and scintillation decay times are presented. Strontium iodide scintillators doped with divalent europium are relatively easy to grow by the vertical Bridgman technique with minimal europium segregation. Crystals doped with trivalent cerium and monovalent sodium as charge compensation show a slight cerium segregation with $\mathrm{K}<1$. $\operatorname{SrI}_{2}: 5 \%$ Eu shows a high light yield of up to $120,000 \mathrm{ph} / \mathrm{MeV}$ and has an excellent energy resolution of $3 \%$ at $662 \mathrm{keV}$. The proportionality of $\operatorname{SrI}_{2}: \mathrm{Eu}$ and $\operatorname{SrI}_{2}: \mathrm{Ce} / \mathrm{Na}$ is much better than that of NaI:Tl and rivals that of $\mathrm{LaBr}_{3}: \mathrm{Ce}$. The already excellent performance of these scintillators holds much promise for future crystal growth and for the use of $\mathrm{SrI}_{2}: \mathrm{Eu}$ and $\mathrm{SrI}_{2}: \mathrm{Ce} / \mathrm{Na}$ in applications where a high light yield and good energy resolution are required. 
Table I. Scintillation properties of $\mathrm{SrI}_{2}: \mathrm{Eu}$ and $\mathrm{SrI}_{2}: \mathrm{Ce} / \mathrm{Na}$.

\begin{tabular}{|l|c|c|c|}
\hline Crystal & $\begin{array}{c}\text { Light Yield } \\
(\mathrm{ph} / \mathrm{MeV})\end{array}$ & $\begin{array}{c}\text { Energy resolution at } 662 \mathrm{keV} \\
(\%)\end{array}$ & $\begin{array}{c}\text { Decay } \\
(\mathrm{ns})\end{array}$ \\
\hline $\mathrm{SrI}_{2}: 0.5 \% \mathrm{Eu}$ & 68,000 & 5.3 & 1100 \\
\hline $\mathrm{SrI}_{2}: 5 \% \mathrm{Eu}$ & 120,000 & 3.0 & 1200 \\
\hline $\mathrm{Sr}_{2}: 8 \% \mathrm{Eu}$ & 80,000 & 6.7 & 1100 \\
\hline $\mathrm{SrI}_{2}: 0.5 \% \mathrm{Ce} / \mathrm{Na}$ & 16,000 & 6.4 & $27(25 \%), 450(75 \%)$ \\
\hline $\mathrm{Sr}_{2}: 2 \% \mathrm{Ce} / \mathrm{Na}$ & 10,114 & 12.2 & $33(46 \%), 570(54 \%)$ \\
\hline
\end{tabular}

\section{REFERENCES}

[1] E. V. D. van Loef, P. Dorenbos, C. W. E. van Eijk, K. Kramer and H. U. Güdel, "High-energy-resolution scintillator: $\mathrm{Ce}^{3+}$ activated $\mathrm{LaBr}_{3}$, " Appl. Phys. Lett., vol. 79, no. 10, pp. 1573-1575, Sep. 2001.

[2] K. S. Shah, J. Glodo, M. Klugerman, W. W. Moses, S. E. Derenzo, M. J. Weber, "LaBr $:$ Ce Scintillators for Gamma-Ray Spectroscopy," IEEE Trans. Nucl. Sci., vol. 50, no. 6, pp. 2410-2413, Dec. 2003.

[3] K. S. Shah, J. Glodo, W. Higgins, E. V. D. van Loef, W. W. Moses, S. E. Derenzo, M. J. Weber, " $\mathrm{CeBr}_{3}$ scintillators for gamma-ray spectroscopy," IEEE Trans. Nucl. Sci., vol. 52, no. 6, pp. 3157-3159, Dec. 2005.

[4] W. M. Higgins, A. Churilov, E. van Loef, J. Glodo, M. Squillante and K. Shah, "Crystal growth of large diameter $\mathrm{LaBr}_{3}: \mathrm{Ce}$ and $\mathrm{CeBr}_{3}, " J$. Crystal Growth, vol. 310, no. 7-9, pp. 2085-2089, Apr. 2008.

[5] R. Hofstadter, "Europium-activated Strontium Iodide Scintillators," US Patent 3,373,279 (1968).

[6] N. J. Cherepy, G. Hull, A. D. Drobshoff, S. A. Payne, E. van Loef, C. M. Wilson, K. S. Shah, U. N. Roy, A. Burger, L. A. Boatner, W.-S. Choong and W. W. Moses, "Strontium and barium iodide high light yield scintillators," Appl. Phys. Lett., vol. 92, no. 8, pp. 083508 1-3, Feb. 2008.

[7] H. Bärnighausen, E. Th. Rietschel, "Die Elementarzelle und Raumgruppe von Strontiumjodid," Z. anorg. allg. Chem., vol. 354, no. 1-2, pp. 23-26, Sep. 1967.

[8] W. S. Choong, W. W. Moses, K. M. Vetter, G. Hull, S. A. Payne, et al., "Design of a facility for measuring scintillator non-proportionality," IEEE Trans. Nucl. Sci., vol. 55, accepted for publication, 2008.

[9] P. Dorenbos et al., "Non-proportionality in the scintillation response and the energy resolution obtainable with scintillation crystals," IEEE Trans.Nucl. Sci., vol. 42, no. 6, pp. 2190-2190, Dec. 1995. 